\title{
BMJ Global Health Health systems research on access to medicines: unpacking challenges in implementing policies in the face of the epidemiological transition
}

\author{
Maryam Bigdeli, ${ }^{1}$ Zubin Cyrus Shroff, ${ }^{2}$ Isabelle Godin,, ${ }^{3}$ Abdul Ghaffar ${ }^{2}$
}

To cite: Bigdeli $\mathrm{M}$,

Shroff ZC, Godin I, et al. Health systems research on access to medicines: unpacking challenges in implementing policies in the face of the epidemiological transition. BMJ Glob Health 2018;2:e000941. doi:10.1136/ bmjgh-2018-000941

Received 7 May 2018 Accepted 9 May 2018
Check for updates

(C) Author(s) (or their employer(s)) 2018. Re-use permitted under CC BY-NC. No commercial re-use. See rights and permissions. Published by BMJ.

${ }^{1}$ World Health Organization, Rabat, Morocco

${ }^{2}$ Alliance for Health Policy and Systems Research, World Health Organization, Geneva, Switzerland

${ }^{3}$ Université Libre de Bruxelles, Brussels, Belgium

Correspondence to Dr Maryam Bigdeli; bigdelim@who.int
Access to medicines is defined by WHO as ensuring that medicines are 'available within the context of functioning health systems at all times in adequate amounts, in the appropriate dosage forms, with assured quality and adequate information, and at a price the individual and community can afford'. ${ }^{1}$ The availability of essential medicines in public health facilities is often poor in the public sector of low-income and middle-income countries (LMICs). For selected generic medicines, availability is between $38 \%$ and $46 \%$. Availability is better in the private sector but also suboptimal at around 70\%. ${ }^{1}$ In some LMICs, prices of selected lowest priced generics can be more than twice the international reference prices, making these unaffordable for patients and the system. ${ }^{2}$ The recently concluded Lancet Commission on Essential Medicines for Universal Health Coverage has proposed a larger set of indicators that monitor the formulation and implementation of national medicines policies, ${ }^{3}$ including quality of essential medicines and disaggregation of indicators to reflect specific access issues for vulnerable populations.

However, despite these efforts at defining, measuring and improving access, the underlying systemic causes of lack of access to medicines are seldom investigated. Bigdeli et al argue that access to medicines should be examined more broadly than within the narrow boundaries of the pharmaceutical sector ${ }^{4}$ : critical factors determining medicines' access are also found in other sub-systems of the health sector (including health financing, human resources for health and health information), at all levels from local to international and on both the supply-side and the demand-side.

In 2011, the Alliance for Health Policy and Systems Research, WHO issued a call for research to generate new knowledge to inform this broad understanding of access to medicines. ${ }^{5}$ The objective of the call was to examine issues around access to medicines beyond the usual indicators of price, availability and rational use, focusing instead on research exploring determinants of medicines' access, including lack of financial protection, bottlenecks related to human resources and the role of the health information system. The scope of the call was informed by a priority-setting exercise to develop research questions that would be particularly relevant to decision-makers in LMICs. ${ }^{6}$ This consisted of a scoping of the literature, key informant interviews and consensus-building workshops in 17 countries across 5 regions, followed by a global expert meeting where priority questions were debated and ranked.

Sixty-seven research proposals were received in response to the call, and after review seven of these proposals (from Brazil, Cambodia, Cameroon, China, India, Nepal and Uganda) were selected for funding. The projects were carried out with technical backstopping from the School of Public Health at the Université Libre de Bruxelles in Belgium. This series reports on results from five of these seven research projects, while findings from projects in China and Cameroon are reported elsewhere. Although not specifically a focus of the call for proposals, one element that strongly links these research projects together is a focus on how national and subnational entities have practically implemented national medicines policies at different levels of the health system, particularly at the district level and the challenges they have faced in this, something that emerged from projects' focus on operational bottlenecks that hamper population access. Another element common to three of the five projects discussed here 
is their focus on non-communicable diseases (NCDs), especially diabetes and hypertension (Brazil, Cambodia, India). Access to medicines challenges in the area of NCDs is of particular relevance for LMIC health systems that were largely designed to address issues of communicable diseases but where, in the face of the epidemiological and demographic transitions, service delivery must juggle between the remaining burden of communicable diseases and the emerging challenges of NCDs. Finally, studies from Nepal and Brazil have another element in common, in terms of exploring programmes to finance medicines through public sources or subsidies.

The findings from Nepal and Cambodia ${ }^{7}$ bring to the fore the challenges of effectively designing and implementing policies to provide free medicines at point of care overcoming systemic and financial bottlenecks to their sustainability. In both cases medicines are in theory free at point of care, but in practice, population access is poor. In the case of Cambodia, a clearly defined package of care for the long-term treatment of diabetes and hypertension at the primary care level, as well as an adequate referral system, are missing, which creates a situation where the short-term treatment of diabetes and hypertension at the secondary or tertiary level becomes the norm. The case of Nepal is characterised by frequent stock-outs, substantial variations in the quality of medicines and services, as well as a general distrust in public health services. In both cases a largely unregulated private sector is benefiting from poorly implemented free medicines policies in the public sector, while patients pay large amounts out-of-pocket (OOP) for life-saving or lifelong chronic treatments.

Luiza et al present an alternate model of subsidising medicines for diabetes and hypertension through the Farmacia Popular model in Brazil. ${ }^{8}$ The study examines a nationwide subsidy scheme that was gradually phased in to cover both private and public retailers, with modifications along the way to mitigate adverse outcomes seen. For example, while copayments were initially allowed under the programme, they reached unexpected levels and a new set of reforms (Saúde Nao Tem Preço) introduced a zero copayment policy while at the same time reinforcing monitoring and control mechanisms. The study raises equity issues as the geographical implementation of the programme has been found to favour relatively richer areas of the country, ${ }^{9}$ but access to diabetes and hypertension medicines improved overall and the programme contributed to a strengthened medicines information system nationwide. ${ }^{8}$

The case of Cambodia also underlines the importance of and the struggles around access to medicines for lifelong chronic conditions such as diabetes and hypertension in countries that are rapidly moving through the epidemiological transition while still facing a substantial burden of communicable diseases and maternal and child mortality. Jacobs $e t a l^{7}$ point that the public health system in Cambodia has been developed along the principles of a district model geared towards fighting communicable diseases. Health centres are not prepared or equipped to deliver appropriate longterm care for patients living with diabetes and hypertension, enabling the private sector to fill the void. At the same time, populations have also to cope with the new epidemics of NCDs; this creates a need for appropriate and mutual adjustments, as evidenced in the papers from the Indian and the Cambodian studies. Jacobs $e t a l^{7}$ plea for urgent action based on the principles of the diagonal approach, ${ }^{10}$ which would integrate diabetes and hypertension care with HIV/AIDS services, carried out in tandem with a reform reorienting the health system towards the type of care required by chronic lifelong conditions-such as a strong primary healthcare system with the capacity to implement disease management programmes and support an effective continuum of care from the community to specialised hospital care.

Similarly, Elias $e a^{11}$ present findings from their study in India, where district health systems in Karnataka are not prepared to organise care for chronic conditions. Services still focus on curative care for communicable diseases, and financial and resource flows accordingly follow the same pattern. As a consequence, patients depend on expensive and episodic care in the largely unregulated private sector, repeating a situation familiar to district-level health systems in many LMICs. This is accompanied by another paper by Aivalli et $a l^{12}$ based on the same research project in Tumkur, Karnataka. While Elias et $a l^{11}$ focus on the supply-side and district preparedness for chronic care, the latter paper by Aivalli et $a l^{12}$ explores the demand-side determinants and finds a general distrust in generic medicines dispensed in public health facilities. It delves deeper into the potential role of private interests in mediating this distrust and finds that, on account of this role, strategies solely focused on improving public supply of services will not be sufficient. Multifaceted approaches are thus needed that also spur demand and control pressures from the private sector.

Concern over NCDs should not overshadow the significant burden of communicable diseases in many countries and the growing threat of antimicrobial resistance that can have dramatic local and global implications. Creative solutions can however be implemented, taking the district as a unit of intervention, as demonstrated by Kitutu et al in Uganda. ${ }^{13}$ The paper reports on an experiment of training retail drug shops to apply community case management guidelines for children with fever. This includes rapid tests for malaria to deliver adequate and appropriate rather than presumptive treatment, an approach that is particularly relevant in districts with low malaria prevalence. This multifaceted study shows that it is possible to design an intervention that supports implementation of medicines regulations and quality standards among private sector providers while simultaneously engaging these actors in delivering on public health objectives and increasing the population's trust in district health services. The 
question remains however on how such innovative interventions can be taken to scale.

This series of papers taken together demonstrates challenges faced by public health systems in enabling access to medicines and how often the private sector fills the gap by default in varied settings around the globe. The failure to recognise this challenge and act on it has serious implications for reaching the objectives of Universal Health Coverage, including quality and equity. Ensuring access to medicines requires carefully balancing multiple needs and interests: reducing the burden of OOP expenditures while putting in place sustainable financial arrangements, and ensuring availability and quality while taking into account patients' preferences and maintaining the population's trust. These all require constant renegotiation of priorities between actors of a complex health system. The multicountry research project supported by the Alliance was a crucial step towards a better understanding of the complexity of access to medicines in the health systems of LMICs. Guided by the principles of Systems Thinking for Health Systems Strengthening, ${ }^{14}$ this research programme broke new ground in research on access to medicines by moving away from a framing of access to medicines prioritising pills and prescriptions, to one putting people rather than products at the centre of enquiry.

Contributors MB and ZS conceptualised the paper. MB wrote the first draft. MB, $Z S, I G$ and $A G$ all contributed to the final version.

Funding The authors have not declared a specific grant for this research from any funding agency in the public, commercial or not-for-profit sectors.

Competing interests None declared.

Patient consent Not required.

Provenance and peer review Not commissioned; internally peer reviewed. Data sharing statement № additional data are available.

Open access This is an open access article distributed in accordance with the Creative Commons Attribution Non Commercial (CC BY-NC 4.0) license, which permits others to distribute, remix, adapt, build upon this work non-commercially, and license their derivative works on different terms, provided the original work is properly cited, appropriate credit is given, any changes made indicated, and the use is non-commercial. See: http://creativecommons.org/licenses/by-nc/4.0/.

\section{REFERENCES}

1. World Health Organization. Global Health Observatory (GHO) data: Median consumer price ratio of selected generic medicines. http:// www.who.int/gho/mdg/medicines/availability_text/en/

2. World Health Organiwation. Global Health Observatory (GHO) data: Median consumer price ratio of selected generic medicines. http:// www.who.int/gho/mdg/medicines/price/en/

3. Wirtz V, Hogerzeil H, Gray A, et al. Essential medicines for universal health coverage. The Lancet 2016;389:31599-9.

4. Bigdeli M, Jacobs B, Tomson G, et al. Access to medicines from a health system perspective. Health Policy Plan 2013;28:692-704.

5. Alliance for Health Policy and Systems Research. Access to Medicines Programme. http://www.who.int/alliance-hpsr/projects/ medicines/en/

6. Bigdeli M, Javadi D, Hoebert $\mathrm{J}$, et al. Health policy and systems research in access to medicines: a prioritized agenda for low- and middle-income countries. Health Res Policy Syst 2013;11:37.

7. Jacobs B, Men C, Bigdeli M, et al. Limited understanding, limited services, limited resources: patients' experiences with managing hypertension and diabetes in Cambodia. BMJ Glob Health 2017;2(Suppl 3):e000235.

8. Luiza VL, Chaves LA, Campos MR, et al. Applying a health system perspective to the evolving Farmácia Popular medicines access programme in Brazil. BMJ Glob Health 2017;2(Suppl 3):e000547.

9. Emmerick IC, do Nascimento JM, Pereira MA, et al. Farmácia Popular Program: changes in geographic accessibility of medicines during ten years of a medicine subsidy policy in Brazil. $J$ Pharm Policy Pract 2015;8:10.

10. Sepúlveda J, Bustreo F, Tapia R, et al. Improvement of child survival in Mexico: the diagonal approach. Lancet 2006;368:2017-27.

11. Elias MA, Pati MK, Aivalli P, et al. Preparedness for delivering non-communicable disease services in primary care: access to medicines for diabetes and hypertension in a district in south India. BMJ Glob Health 2017;2(Suppl 3):e000519.

12. Aivalli PK, Elias MA, Pati MK, et al. Perceptions of the quality of generic medicines: implications for trust in public services within the local health system in Tumkur, India. BMJ Glob Health 2017;2(Suppl 3): $\mathrm{e} 000644$

13. Kitutu FE, Mayora C, Johansson EW, et al. Health system effects of implementing integrated community case management (iCCM) intervention in private retail drug shops in South Western Uganda: a qualitative study. BMJ Glob Health 2017;2(Suppl 3):e000334.

14. In: Adam T, De Savigny D, eds. Systems thinking for health systems strengthening. Geneva, Switzerland: Alliance for Health Policy and Systems Research, World Health Organization, 2010. 